\title{
Trade Liberalization and Technology Transfer through an Intermediate Product*
}

\author{
Jota Ishikawa $^{\dagger}$ \\ Hitotsubashi University
}

\begin{abstract}
Horiuchi and Ishikawa (2007) examine the relationship between tariffs on the final good and international technology transfer through trade in an intermediate good. They show that a decrease in the tariff as well as an increase may lead the North monopolist to transfer technology to a South potential entrant. This paper shows that tariff-reductions may induce technology transfer even if technologytransfer competition among multiple North firms is taken into account.
\end{abstract}

Keywords: technology transfer, intermediate products, tariffs, licensing, North-South trade JEL Classification: F12, F21, F23

\section{Introduction}

International technology transfer has attracted widespread attention in the international trade literature. Constructing a simple oligopolistic model, Horiuchi and Ishikawa (2007) examine the relationship between tariffs and technology transfer from developed countries (the North) to developing countries (the South). They are specifically concerned with technology transfer through trade in an intermediate good. The essence of technology is often embodied in sophisticated intermediate products which the South is unable to produce ${ }^{1)}$. In this case, even if know-how to produce final products is known to the South, they cannot produce those final products by themselves. To produce the final products, they have to import such key inputs from the North. For example, when Hyundai Motor Co. (a Korean auto maker) manufactured the first Korean car in 1975, the engine was pro-

Final version accepted 12 June 2007.

* This paper is partly on the basis of my lecture given at the ceremony of Kiyoshi Kojima Prize at the 65 the annual meeting of the Japan Society of International Economics held at Nagoya University. I acknowledge financial support from the Ministry of Education, Culture, Sports, Science and Technology of Japan under the 21st Century Center of Excellence Project.

† Corresponding author: Faculty of Economics, Hitotsubashi University, Kunitachi, Tokyo 186-8601, Japan; Fax: +81-42580-8195; E-mail: jota@econ.hit-u.ac.jp

1) Coe et al. (1977) point out that between 1971 and 1977, R\&D in the North increased total factor productivity in the South through their imports of intemediate products and capital goods from the North. 
vided by Mitsubishi Motors Co. (a Japanese auto maker), which transferred its technology to Hyundai ${ }^{2}$.

In Horiuchi and Ishikawa (2007), a North firm (firm $N_{1}$ ) initially monopolizes the South final-good market. Firm $N_{1}$ serves the market by exports. They show that an increase in the tariff on the final good may induce technology transfer from firm $N_{1}$ to a potential entrant in the South (firm $S$ ). As the tariff increases, the profits of firm $N_{1}$ decrease. In order to offset the loss, it transfers technology to a potential local entrant by selling the essential intermediate product. That is, an increase in the tariff on the final good may cause the "tariff-jumping" technology transfer from the North to the South.

They also show that a decrease in the tariff on the final good may lead to technology transfer. In their model, there is another North firm (firm $N_{2}$ ) which is also a potential entrant to the South final-good market. Firm $N_{2}$ has to incur some fixed costs to start exporting its product to the South. In the absence of firm $\mathrm{N}_{2}$, a decrease in the tariff on the final good never results in technology transfer. When the tariff becomes low enough for firm $N_{2}$ to cover its FC, however, firm $N_{2}$ starts exporting to the South. For firm $N_{1}$, the duopoly between firms $N_{1}$ and $S$ is preferable to the duopoly between firms $N_{1}$ and $N_{2}$, because not only firm $N_{1}$ gains from selling the intermediate good to firm $S$ but also firm $S$ is less efficient than firm $N_{2}$. Thus, firm $N_{1}$ strategically lets firm $S$ enter the market just before firm $N_{2}$ enters. That is, a decrease in the tariff on the final good may result in the "entry-deterring" technology transfer from the North to the South.

The purpose of this paper is to show that tariff-reductions may induce technology transfer in an extended model in which both firms $N_{1}$ and $N_{2}$ are incumbents, that is, the initial market structure is the duopoly between firms $N_{1}$ and $N_{2}$. When trade is liberalized, the firms may have an incentive for technology transfer. Since there are two potential technology suppliers, we have to take the interaction between these firms into account. We specifically examine a case in which firm $N_{1}$ is more efficient than firm $N_{2}$ in production of intermediate goods.

Strategic technology transfer (such as strategic licensing) within a closed economy has received extensive attention in the industrial organization literature ${ }^{3)}$. However, strategic aspects of international technology transfer have not been analyzed as extensively as those of domestic technology transfer. Kabiraj and Marjit (2003) and Mukherjee and Pennings (2006) point out the possibility of "tariff-induced" technology transfer through licensing. Using a duopoly model, Kabiraj and Marjit (2003) show that the foreign firm has an incentive to license its superior technology to the domestic rival only if the initial cost-difference between the foreign and domestic firms is small. By reducing the cost-difference, a tariff may induce licensing. Mukherjee and Pennings (2006) consider the relationship between licensing by the foreign monopolist to potential entrants and the timing of the imposition of the (optimal) tariff.

Lin and Saggi (1999), Pack and Saggi (2001), and Ishikawa and Horiuchi (2007) also indicate other strategic uses of the North-South technology transfer. Lin and Saggi (1999) show a paradoxical result that technology

2) Similar examples include a Malaysian auto maker, Proton, established in 1983 and another Korean auto maker, Samsung Motors, established in 1994. Mitsubishi Motors Co. and Nissan Motor Co., Ltd., respectively, provided technological assistance to Proton and Samsung.

3 ) For example, see Gallini (1984), Rockett (1990), and Arya and Mittendorf (2006). 
spillovers through FDI may facilitate FDI rather than discourage it in a dynamic North-South model. This is because FDI makes the South firm's imitation of an advanced technology easier and intensifies competition in the South market and hence FDI undertaken by one of the North firms may delay the other North firm's switch from exports to FDI. Similarly, Ishikawa and Horiuchi (2007) point out that technology spillovers through FDI may benefit the investing firm. In their model, vertically related markets play a crucial role. Spillovers to the South downstream firm affect the pricing behavior of the upstream firm. This may soften double marginalization in vertically related markets and benefit the North downstream firm. In fact, technology spillovers through FDI may result in Pareto gains. Pack and Saggi (2001) also show a possibility of Pareto-improving technology transfer in vertically related markets. However, Pack and Saggi (2001) are primarily concerned with vertical technology transfer (through outsourcing).

The rest of the paper is organized as follows. Section 2 presents the basic model. Section 3 investigates the effects of trade liberalization on technology transfer. Section 4 concludes the paper.

\section{The Basic Model}

There are two countries, the North and the South. We consider the interactions among two incumbents in the North, firms $N_{1}$ and $N_{2}$, and a potential entrant in the South, firm $S$. Firms produce homogenous final goods and engage in Cournot competition in the South market. Firms $N_{1}$ and $N_{2}$ export their final goods to the South ${ }^{4)}$.

To start production, firm $S$ needs to have technology transferred from a North firm, that is, firm $S$ has to purchase a key intermediate good from one of the North firms. Firms $N_{1}$ and $N_{2}$ have two different technologies and compete for technology transfer to firm $S$. Each technology requires a specific intermediate good. That is, the intermediate goods produced by firms $N_{1}$ and $N_{2}$ are differentiated. Firm $S$ adopts either of the two technologies. Once one technology is adopted, the other is idle ${ }^{5)}$.

One unit of the intermediate good is required for each unit of the final good. The marginal cost (MC) to produce the intermediate product is zero for firm $N_{1}$ and $c(>0)$ for $N_{2}$. Firm $S$ purchases the intermediate good at price $r$. The MC to produce the final good from the intermediate good is zero for all firms.

The South government imposes a specific tariff on the intermediate good, $T$, as well as a specific tariff on the final good, $t$. The inverse demand is given by the following linear function: ${ }^{6)}$

$$
p(X)=b-a X,
$$

4) We assume away FDI by the North firms. Firms refrain from FDI in the presence of high setup costs of FDI and high risk of expropriation, for example.

5 ) For example, typical eco-friendly cars are currently hybrid vehicles and diesel vehicles. Their engines are completely different. Once a firm decides to manufacture hybrid cars, for instance, diesel engines are useless. Similar examples include plasma display panel vs. liquid crystal display panel in TV production and Blu-ray Disc vs. High-Definition Digital Versatile Disc (HD DVD) in DVD-player production.

6) Even if the demand function is non-linear, the essence of our results would not change. 
where $p$ and $X$ are, respectively, the price and the demand of the final good. $a$ and $b$ are parameters.

The model involves four stages of decision. In stage 0 , the South government determines the tariff rates. In stage 1, firms $N_{1}$ and $N_{2}$ decide whether to transfer technology to firm $S$ and whether to serve the final-good market. If it decides to transfer technology, firms $N_{1}$ and $N_{2}$ offer the intermediate-good prices. In stage 2, firm $S$ decides whether to accept the offer. In stage 3, the firms compete in the final-good market. The game is solved by backward induction.

\section{Tariffs and Technology Transfer}

In this section, we show that tariff-reductions may induce technology transfer from firm $N_{1}$ to firm $S$. The benchmark is a case without technology transfer, that is, the duopoly between firms $N_{1}$ and $N_{2}$.

Given $t$, the duopoly equilibrium is given by

$$
\begin{gathered}
x_{N_{1}}^{N N}(t)=\frac{b+(c+t)-2 t}{3 a}, x_{N_{2}}^{N N}(t)=\frac{b+t-2(c+t)}{3 a}, \\
\pi_{N_{1}}^{N N}(t)=\frac{(b+(c+t)-2 t)^{2}}{9 a}, \pi_{N_{2}}^{N N}(t)=\frac{(b+t-2(c+t))^{2}}{9 a},
\end{gathered}
$$

where a superscript " $N N$ " stands for the duopoly between firms $N_{1}$ and $N_{2}$ (henceforth the $N N$ duopoly). $c<$ $(b-t) / 2$ is necessary for $x_{N_{2}}^{N N}(t)>0$.

If firm $S$ enters the market, we have three possible market structures. In the first case, all firms serve the market. Given $r$ and $t$, we have

$$
\begin{aligned}
& x_{N_{1}}^{N N S}(r ; t)=\frac{b+(c+t)+r-3 t}{4 a}, \\
& x_{N_{2}}^{N N S}(r ; t)=\frac{b+t+r-3(c+t)}{4 a}, \\
& x_{S}^{N N S}(r ; t)=\frac{b+t+(c+t)-3 r}{4 a},
\end{aligned}
$$

where a superscript " $N N S$ " stands for the oligopoly among firms $N_{1}, N_{2}$ and $S$ (henceforth the $N N S$ oligopoly). $x_{N_{2}}^{N N S}(r ; t)>0$ (i.e., $\left.b+r-3 c-2 t>0\right)$ and $x_{S}^{N N S}(r ; t)>0$ (i.e., $b+c-3 r+2 t>0$ ) are necessary for the $N N S$ oligopoly.

In the second case, firms $N_{1}$ and $S$ serve the market:

$$
x_{N_{1}}^{N S}(r ; t)=\frac{b+r-2 t}{3 a}, x_{S}^{N S}(r ; t)=\frac{b+t-2 r}{3 a},
$$

where a superscript " $N S$ " stands for the duopoly between firms $N_{1}$ and $S$ (henceforth the $N S$ duopoly). $x_{N_{1}}^{N S}(r ; t)>0$ (i.e., $b+r-2 t>0)$ and $x_{S}^{N S}(r ; t)>0$ (i.e., $\left.b+t-2 r>0\right)$ are necessary for the $N S$ duopoly.

In the last case, only firm $S$ serves the market: 


$$
x_{S}^{S}(r ; t)=\frac{b-r}{2 a},
$$

where a superscript " $S$ " stands for the monopoly by firm $S$ (henceforth the $S$ monopoly).

We now consider the second stage. In this stage, firms $N_{1}$ and $N_{2}$ compete for technology transfer. Since firm $N_{1}$ is more efficient than firm $N_{2}$ in production of the intermediate goods, firm $N_{1}$ provides the intermediate good to firm $S$ in equilibrium. The price firm $N_{1}$ charges is less than or equal to $c$.

Under the NNS oligopoly, firm $N_{1}$ maximizes

$$
\pi_{N_{1}}^{N N S}(r ; t, T)=\frac{(b+(c+t)+r-3 t)^{2}}{16 a}+(r-T) \frac{b+t+(c+t)-3 r}{4 a}
$$

subject to $r \leq c+T . \pi_{N_{1}}^{N N S}(r ; t, T)$ takes its maximum value at $r^{N N S}(t, T)=(6 T+3 b+3 c+2 t) / 11$ without any constraint. The constraint is binding if $c \leq(3 b-5 T+2 t) / 8\left(\equiv c_{1}\right)$. Intuitively, the constraint is likely to bind when $c$ is small.

Under the $N S$ duopoly, firm $N_{1}$ maximizes

$$
\pi_{N_{1}}^{N S}(r ; t, T)=\frac{(b+r-2 t)^{2}}{9 a}+(r-T) \frac{b+t-2 r}{3 a}
$$

subject to $r \leq c+T . \pi_{N_{1}}^{N S}(r ; t, T)$ takes its maximum value at $r^{N S}(t, T)=(6 T+5 b-t) / 10$ without any constraint. The constraint is binding if $c \leq(-4 T+5 b-t) / 10\left(\equiv c_{2}\right)$.

Under the $S$ monopoly, firm $N_{1}$ maximizes

$$
\pi_{N_{1}}^{S}(r ; T)=(r-T) \frac{b-r}{2 a}
$$

subject to $r \leq c+T . \pi_{N_{1}}^{S}(r ; T)$ takes its maximum value at $r^{S}(T)=(b+T) / 2$ without any constraint. The constraint is binding if $c \leq(b-T) / 2\left(\equiv c_{3}\right)$.

We are now ready to establish the following proposition.

Proposition 1 Trade liberalization may lead firm $N_{1}$ to transfer technology to firm $S$.

Trade liberalization means simultaneous reductions of $t$ and $T$. For simplicity, therefore, we assume $T=k t$, where $k$ is constant. Then a reduction of $t$ implies that of $T$ as well. The appendix shows that under the following parameter values, for example, the market structure shifts from the $N N$ duopoly to the $N N S$ oligopoly as trade is liberalized:

$$
c=\frac{701}{2600} b, \frac{b}{200}<t_{0}<\frac{599}{13000} b, k=4,
$$

where to is the intial $t$ Trade liberalization lowers both $t$ and $T$. Intuitively, when the degree of the reduction of $T$ exceeds that of $t$, trade liberalization makes the benefit from exporting the intermediate good larger. The degree of the reduction of $T$ relative to that of $t$ is reflected in $k$. Thus, when $k$ is relatively large, trade liberalization is likely to induce technology transfer. It should be noted, however, that the initial $T, T_{0}$, is not prohibitive under (8), that is, $\hat{x}_{S}^{N N S}(t, T)>0$ holds at $T_{0}$ (see the appendix). 


\section{Concluding Remarks}

Horiuchi and Ishikawa (2007) showed that a decrease in the tariff on the final good as well as an increase may induce technology transfer from the North to the South. We have examined the relationship between trade liberalization and technology transfer in an extended model. Whereas the initial market structure is the monopoly by a North firm with two potential entrants in Horiuchi and Ishikawa (2007), ours is the duopoly between two North firms with a local potential entrant. Assuming that one of the North firms is more efficient in production of the intermediate good than the other North firm, we have shown that trade liberalization may induce technology transfer even if technology-transfer competition among multiple North firms is taken into account.

Following Horiuchi and Ishikawa (2007), we have specifically assumed that technology is embodied in a key component which only the North can produce. As pointed out in Horiuchi and Ishikawa (2007), we can easily incorporate licensing into our analysis. In particular, we can simply reinterpret the price of the intermediate good as the sum of the price of the intermediate good and the per-unit royalty. Focusing on technology transfer through trade in intermediate goods rather than licensing, however, we can not only get rid of arguments over the optimal licensing contracts ${ }^{7)}$ but also argue that North firms may have an incentive to transfer their technologies to South firms even if the licensing market does not exist or is restricted, which has been observed in many developing countries ${ }^{8)}$.

\section{Appendix}

This appendix shows Proposition 1. For this, we find parameter values under which the market structure shifts from the $N N$ duopoly to the $N N S$ oligopoly as trade is liberalized.

When $r=c+T$ under the NNS oligopoly, we obtain

$$
\begin{aligned}
& \hat{x}_{N_{1}}^{N N S}(t, T)=\frac{b+2 c-2 t+T}{4 a}, \\
& \hat{x}_{N_{2}}^{N N S}(t, T)=\frac{b-2 c-2 t+T}{4 a}, \\
& \hat{x}_{S}^{N N S}(t, T)=\frac{b-2 c+2 t-3 T}{4 a},
\end{aligned}
$$

7 ) The licensing literature has extensively compared between per-unit royalty and fixed fee to argue the optimal licensing contracts. See, for example, Wang (1998) and Kamien and Tauman (2002).

8 ) The South governments often demand technology transfer without any payments for licensing. Even if licensing opportunities are present, the South governments sometimes impose various regulations such as a cap on royalty rates. For example, see Davies (1977) for the Indian case and Peck and Tamura (1976) for the Japanese case. 


$$
\begin{aligned}
\hat{\pi}_{N_{1}}^{N N S}(t, T) & =\frac{(b+2 c-2 t+T)^{2}}{16 a}+c \frac{b-2 c+2 t-3 T}{4 a} \\
& =\frac{1}{16 a}\left(2 T b-8 T c+8 b c-4 T t-4 b t+T^{2}+b^{2}-4 c^{2}+4 t^{2}\right),
\end{aligned}
$$

where "hat" stands for equilibrium when the constraint is binding. $c<(b-2 t+T) / 2$ is necessary for $\hat{x}_{N_{2}}^{N N S}(t, T)>0$. Moreover, $c<(b+2 t-3 T) / 2$ is necessary for $\hat{x}_{S}^{N N S}(t, T)>0$. With these constraints, we have

$$
\Delta \pi_{N_{1}}^{N N} \equiv \pi_{N_{1}}^{N N}(t)-\hat{\pi}_{N_{1}}^{N S S}(t, T)=-\frac{1}{144 a}(b-3 T-2 c+2 t)(26 c-7 b-3 T+10 t) .
$$

Thus, $\Delta \Pi_{N_{1}}^{N N}>0$ holds if and only if $c<(7 b-10 t+3 T) / 26\left(\equiv c^{*}\right)$ holds.

Thus, ignoring the possibilities of the NS duopoly and the $S$ monopoly (for the moment), we can establish the following lemma which specifies the conditions under which the benchmark case (i.e., the $N N$ duopoly) exists.

Lemma 1 Suppose $r=c+T$, or, $c \leq c_{1}$. Also suppose $c<\min \{(b-t) / 2,(b-2 t+T) / 2,(b+2 t-3 T) / 2\}$. Then the NN duopoly arises if $c<c^{*}$. The NNS oligopoly arises if $c>c *$.

Under the parameter values (8), $c \leq c_{1}=(3 b-18 t) / 8$ for $t<t_{0}$ and hence the constraint is binding (i.e., $r=$ $c+T)$. Also $c<\min \{(b-t) / 2,(b-2 t+T) / 2,(b+2 t-3 T) / 2\}=(b-10 t) / 2$ holds for $t<t_{0}$. As $t$ falls, $c^{*}(=$ $(7 b+2 t) / 26)$ falls and $c=c^{*}$ holds at $t=b / 200\left(\equiv t^{*}\right)$. Thus, once $t$ becomes lower than $t^{*}$, technology transfer leads to larger profits for firm $N_{1}$.

We next check if the market structure actually shifts from the $N N$ duopoly to the $N N S$ oligopoly. For this, we first consider the $N S$ duopoly. In view of (4), the $N S$ duopoly arises only if $r \leq-(b-3 c-2 t)\left(\equiv r^{*}\right)$. We can verify that with (8), both $r^{*}<(c+T)$ and $c<c_{2}$ hold. Thus, with (8), $r^{*}$ maximizes the profits of firm $N_{1}$ under the $N S$ duopoly

$$
\pi_{N_{1}}^{N S}\left(r^{*} ; t, T\right)=-\frac{1}{a}\left(T b-2 T c-5 b c-T t-3 b t+7 c t+b^{2}+5 c^{2}+2 t^{2}\right) .
$$

Then

$$
\Delta \pi_{N_{1}}^{N S} \equiv \pi_{N_{1}}^{N S}\left(r^{*} ; t, T\right)-\hat{\pi}_{N_{1}}^{N N S}(t, T)=-\frac{1}{16 a}(38 c-17 b-T+18 t)(2 c-b-T+2 t) .
$$

We can verify that with (8), $\Delta \pi_{N_{1}}^{N S}<0$ if $38 c-17 b-T+18 t<0$, that is, $c<(17 b+T-18 t) / 38$. Besides, $c<$ $(17 b+T-18 t) / 38$ actually holds with (8). Thus, firm $N_{1}$ prefers the NNS oligopoly to the NS duopoly with (8).

Moreover, with (8), $c<c_{3}$ holds. When $r=c+T$, we obtain

$$
\hat{\pi}_{N_{1}}^{S}(T)=c \frac{b-(c+T)}{2 a} .
$$

Then

$$
\begin{aligned}
\Delta \pi_{N_{1}}^{S} & \equiv \hat{\pi}_{N_{1}}^{S}(T)-\hat{\pi}_{N_{1}}^{N N S}(t, T)=-\frac{1}{16 a}\left(T^{2}+2 T b-4 T t+b^{2}-4 b t+4 c^{2}+4 t^{2}\right) \\
& =-\frac{4 c^{2}+(T+b-2 t)^{2}}{16 a}<0,
\end{aligned}
$$


Jota Ishikawa : Trade Liberalization and Technology Transfer through an Intermediate Product

which implies that firm $N_{1}$ prefers the $N N S$ oligopoly to the $S$ monopoly. With (8), therefore, Lemma 1 holds even if the possibilities of the $N S$ duopoly and the $S$ monopoly are taken into account.

\section{References}

[1] Arya, A. and Mittendorf, B. (2006) "Enhancing Vertical Effuciency through Horizontal Licensing," Journal of Regulatory Economics 29, 333-342.

[2 ] Coe, D. T., Helpman, E., and Hohhmaister, A. W. (1997) "North-South R\&D Spillover," Economic Journal 107, 134-149.

[ 3 ] Davies, H. (1977) "Technology Transfer through Commercial Transactions," Journal of Industrial Economics 26, 161-175.

[4] Gallini, N. T. (1984) "Deterrence by Market Sharing: A Strategic Incentive for Licensing," American Economic Review 74, 931-941.

[ 5 ] Horiuchi, E. and Ishikawa, J. (2007) "Tariffs and Technology Transfer with an Intermediate Good", COE-RES Discussion Paper Series, No. 201, Hitotsubashi University.

[6] Ishikawa, J. and Horiuchi, E. (2007) "Strategic Technology Transfer through FDI in Vertically Related Markets," mimeo.

[ 7 ] Ishikawa, J. and Spencer, B. J. (1999) "Rent-shifting Export Subsidies with an Intermediate Product," Journal of International Economics 48, 199-232.

[ 8 ] Kabiraj and Marjit (2003) "Protecting Consumers through Protection: The Role of Tariff- induced Technology Transfer," European Economic Review 47, 113-124.

[ 9 ] Kamien, M., Tauman, Y. (2002) “Patent Licensing: The Inside Story," Manchester School 70, 7-15.

[10] Lin, P. and Saggi, K. (1999) “Incentives for Foreign Direct Investment under Imitation," Canadian Journal of Economics 32, 1275-1298.

[11] Mukherjee, A. and Pennings, E. (2006) "Tariffs, Licensing and Market Structure," European Economic Review 50, 1699-1707.

[12] Pack H. and Saggi K. (2001) "Vertical Technology Transfer via International Outsourcing," Journal of Development Economics 65, 389-415.

[13] Peck, M. J. and Tamura, S. (1976) “Technology,” In Patrick, H. and Rosovskt, H. eds. Asia's New Giant: How the Japanese Economy Works, Brookings Institution: Washington.

[14] Rockett, K. E. (1990) "Choosing the Competition and Patent Licensing," RAND Journal of Economics 21, 161171

[15] Wang, X. H. (1998) "Fee versus royalty licensing in a Cournot duopoly model," Economics Letters 60, 55-62. 